Referencia al citar este artículo:

Blanco, J. (2015). Hablar sobre sincronicidad, una tarea pendiente en las aulas. Revista TEMAS, 3(9), 11 -16.

\title{
Hablar sobre sincronicidad, una tarea pendiente en las aulas ${ }^{1}$
}

José Antonio Blanco Villalobos ${ }^{2}$

\section{Resumen}

Como lo menciona la física cuántica, la realidad es una construcción que hacemos nosotros mismos, no es la que está impuesta como tal, al fin de cuentas, otros nos imponen sus realidades con sus construcciones políticas y económicas, pero no tienen por qué ser las nuestras. ¿Por qué no les decimos a los demás que pueden construir sus propias realidades? Cuando una persona creativa observa objetos, no está simplemente mirando cosas, está construyendo posibilidades. La sincronicidad permite a través de la creatividad, el deseo de realizar un proyecto y la energía que dirijamos a conseguirlo, que este sea posible. Es necesario, si queremos transformar América Latina, que nos demos a la tarea de empoderar nuestra gente.

\section{Palabras clave}

Sincronicidad, realidad, creatividad, posibilidades.

\section{Addressing synchronicity, a pending task in class}

\section{Abstract}

We are able to build our reality, because reality is not how we perceive it, all that we think is reality was built by others, but it isn't our. They use the economy and politics to build all we know as reality. Why we do not teach others about how they can build their realities? When a creative person is watching a thing, he isn't simply seeing a thing, he is building possibilities. Synchronicity allowed through creativity, desire to do a project and energy we head to get it, make it possible. If we want to transform Latin America, it is necessary to give ourselves the task of empowering our people.

\section{Keywords}

Synchronicity, reality, creativity, possibilities.

1 Artículo de reflexión.

2 Doctorado en Educación con especialidad en Mediación Pedagógica por la Universidad de La Salle, Costa Rica. Correo electrónico: blanco. tony@gmail.com 


\section{Introducción}

La sincronicidad es un concepto acuñado por Carl Jung que se refiere a las "coincidencias significativas" de eventos que se relacionan entre sí pero de forma no causal, y son significativas porque no son producto del azar, sino del deseo de quien las invoca, tienen sentido para aquella persona que traza una meta $y$ comienza a trabajar en ella, en otras palabras, a través de este fenómeno podemos lograr que las cosas sucedan, pero teniendo en cuenta que la sincronicidad no la controlamos nosotros, sucede porque dirigimos nuestra energía en ese sentido y en ese proceso emergen y se sincronizan muchos elementos que son necesarios para que nuestra idea u objetivo pueda cumplirse. Emprender un camino, configurará nuevas realidades, porque en cada momento de nuestras vidas estamos frente a muchas posibilidades simultáneamente, pero elegimos una, y sí, somos nosotros quienes elegimos cómo vamos a abordar estas posibilidades y transformarlas en nuestra realidad, aunque también podemos crearlas. Por lo tanto, propongo la creatividad como abordaje, porque ella es la que hace funcionar nuestro potencial humano y que comencemos a empoderarnos en la construcción de nuestro presente y nuestro futuro, pero para extender esto a América Latina es necesario que los centros educativos sean parte de esta sincronicidad. Antes de disertar sobre sincronicidad, me permitiré plantear algunos elementos que están estrechamente ligados a este fenómeno universal, aunque debo advertir que no son los únicos.

\section{Reflexiones sobre "la realidad"}

A este respecto, los autores del libro Y tú qué sabes, anotan:

¿Qué es la realidad? La mayoría de la gente cree que la realidad es lo que los sentidos proyectan ante nosotros. Y la ciencia desde luego, ha apoyado esta visión durante cuatrocientos años: si no percibimos algo a través de los cinco sentidos (o de sus extensiones) no es real (Arnz, Chasse, Vicente, 2006. p. 48).

Basta solo con tener una afección como el daltonismo para percibir diferente los colores y por tanto construir una realidad distinta, pero, ¿distinta a la de quién? El problema es que las instituciones de enseñanza se han dado a la tarea (y para nadie esto es un secreto) de "normalizar"; o sea, se establecen parámetros de interpretación de los objetos, de las conductas y las acciones, pero de manera "objetiva", en otras palabras, en un solo sentido de expresión que no dan cabida a terceras ideas porque son consideradas "anormales". Al entender de Maturana, citado por Denise Najmanovich (2014) “la objetividad es una petición de obediencia". Por eso me cuestiono: ¿obediencia a quién o a qué?

De esta manera, hemos convertido con el paso del tiempo la espiritualidad en religión y la religión en moralidad y terminamos interpretando a partir de esta última el esquema de valores espirituales. Si me porto bien, no hago esto o aquello, entonces soy espiritual...

Como sociedades vamos construyendo códigos de conducta, interpretación y expresión que devienen con la imposición de unos y el consenso de otros en "cultura", la cual transmitimos de generación en generación a través de varios fenómenos. Uno es el que transmitimos en el seno de nuestra familia y comunidades, otro es, al entender de Jung (2008), cuando construimos arquetipos y elaboramos inconscientes colectivos, entonces como sociedad buscamos construir una identidad cultural y estos fenómenos sociales los hacemos parte de nuestra realidad, el problema no es ese, el problema es que muchas veces se imponen estos aspectos desde fuera de nosotros y nuestras vidas. 
De esta forma, tales aspectos pueden generar la negación de lo subjetivo y lo relativo, por tanto, negamos al otro y lo otro como un legítimo otro, pues como un otro, tiene el derecho de expresar su ser en otra dimensión de la realidad que habita, o sea, puede trascender el discurso social al que pertenece y construir el suyo propio aunque no sea considerado "normal". Un ejemplo típico de esto son las personas consideradas excéntricas, una tipificación que permite "justificar" sus conductas no habituales ante la imposibilidad de cambiarlas, pues tienen cierto poder mediático, económico o político. De esta manera se puede justificar el discurso social de normalización y evitar la subversión.

Como lo ha manifestado Francisco Gutiérrez Pérez (2014), la educación es una praxis política, cuyo compromiso no solo es teórico, y debe serlo porque la vida misma, que es posible gracias al aprendizaje, está constantemente afectada por los aspectos sociales, entre ellos, la política, que a través de los intereses de unos cuantos, construyen y constituyen una "realidad" para su pueblo, pero es una "realidad" que niega el potencial, la creatividad y las capacidades de muchas gentes, porque se estandariza el pensamiento de ciertos individuos. El libro ¿Y tú qué sabes? al respecto de paradigmas nos dice: "¿Has hecho alguna vez galletas de Navidad utilizando el mismo molde? Pongas los ingredientes que pongas, todas salen del horno exactamente igual" (Will citado por Arnz, Chasse, Vicente, 2005, p. 37).

Es bajo esta premisa del desarrollo de un pensamiento social estandarizado que tenemos que reaccionar ante lo que significa la realidad, esa que es posible construir desde cada individuo, desde sus potencialidades y su forma de leer el mundo, porque no todos percibimos igual, pero se necesita construir vías para comprender otros puntos de mira, para aceptarlos o validarlos.

Por lo tanto, nosotros mismos podemos cambiar nuestros puntos de mira, abrir nuestros pensamientos y construir nuestra realidad de otra forma. Como dice Chasse (2006): "Si estoy dispuesta a abrir los ojos a nuevas posibilidades, $\mathrm{mi}$ realidad puede cambiar" (Chasse, p. 49).

\section{Algunas ideas sobre percepción}

La percepción es un tema complejo, por tanto abordaré algunas ideas. Para empezar hablaré de la mente, de Bateson (citado por Assmann, 2002) "La unidad de supervivencia es el organismo más su entorno. La unidad de supervivencia es idéntica a la unidad como mente", en otras palabras, no somos seres aislados a nuestra ecología cognoscitiva, así lo afirma Hugo Assmann; por tanto este autor hace referencia a los sentidos desde este punto de vista: "Nuestros sentidos no son ventanas, sino interlocutores con el mundo" (p. 37) en otras palabras, no percibimos desde afuera, sino en interacción con el entorno, al haber del autor, "percibir desde afuera" fue lo que dio origen al concepto emisor-receptor o alumno-profesor como subsistemas del conocimiento; sin embargo, en contraposición a esto, el mismo Assmann (2002) define que el "conocimiento surge mediante el aprendizaje" (p. 35) pero como interacción de varios factores internos del que aprende.

Entonces, tomando en cuenta que la percepción no es un asunto exógeno, Assmann primero advierte que "Las teorías de percepción... generalmente se basan en la idea de transmisión/recepción de información procedente del medio" (p. 38), en contraposición a esto afirma:

Por el contrario, la perspectiva organismo/entorno como sistema unificado resalta dos aspectos: primero, que la percepción es una actividad que abar- 
ca por entero el subsistema cuerpo/ mente; y segundo, que está inserta en el sistema organismo/entorno como un todo, repercutiendo en una organización específica de dos niveles. Esto significa que la percepción se produce como propiedad emergente en el sistema de corporeidad, inserta en el sistema unificado organismo/entorno (2008, p. 38).

Por lo tanto, la percepción es un proceso endógeno en interacción con el "entorno cognoscitivo". Pero, ¿cómo realizamos entonces la interpretación del entorno cuando interactuamos con él? Creo que esto es lo que debemos cuestionarnos, ¿cuál es nuestro abordaje al respecto de percepción? No será que estamos hablando de la interpretación que hacemos de los elementos emergentes del entorno, en vez de percepción. Pues la interpretación de la percepción depende de la forma en que realizamos esa interacción, ya que nuestro cuerpo/mente percibe mucho más de lo que somos conscientes, además que la interpretación la realizamos a partir del estado de consciencia y conocimiento que hemos desarrollado hasta el momento.

Para hablar de interpretación se podrían plantear las siguientes preguntas: ¿Cuánto de su cultura utiliza usted para filtrar la música que escucha o la obra de arte que ve?, ¿cómo está su salud visual o auditiva? Parece ser que cuando hablamos de percepción, lo que estamos abordando es la interpretación consciente que tenemos y no de percepción, porque en realidad, como lo expresa Assmann, percibimos como un sistema unificado organismo/entorno, eso quiere decir que todo nuestro organismo percibe de forma compleja y no solo la parte consciente de nuestra mente, la cual tampoco es endógena.

A este respecto, Arnz, Chasse y Vicente (2006) señalan: “Dado que sólo somos conscientes de 2000 bits de información de los 400000 millones de bits de infor- mación que procesamos por segundo... Cuando alegamos razones en contra del conocimiento nuevo... ¿cuánta "conciencia" nuestra está esgrimiendo esas razones?" (p. 5).

Entonces, la percepción es fundamental en la construcción que hacemos de la realidad, por tanto vale la pena preguntarnos ¿lo que llamamos realidad será debido a nuestra capacidad de percibir, o será la resultante de nuestra incapacidad de ver y sentir más allá, de trascender, de ser uno con el entorno?

Nos son ajenos los sonidos y vibraciones de las hormigas, ¿por qué no escuchamos sus sonidos?, no podemos sentir en su longitud de onda, para ellas somos sordos (O'Brien, 2013).

Igualmente, no podemos oler el rastro bioquímico de los insectos, además en su mundo no tenemos olfato. $Y$ estas son solo algunas de las razones de por qué solo percibimos 2000 bits de información por segundo.

Pero no hay que preocuparse por ello, al fin de cuentas todos los seres coexistimos y cada quien interpreta su realidad desde sus interacciones con el medio que le rodea, pero eso no quiere decir que a través de la creatividad no podamos desarrollar nuevas posibilidades, es por esta razón que no digo que cada quien percibe desde sus posibilidades, porque una cosa son mis interacciones con el medio como sistema complejo, y otras son las posibilidades que emergen frente a nosotros y de las cuales elegimos una o bien las que podemos crear.

\section{Sobre creatividad}

Cuando una persona creativa observa objetos, no está simplemente mirando cosas, está construyendo posibilidades. Esta frase la sustento en la teoría de la inteligencia creadora de José Antonio Marina, en la que nos dice que "la inteli- 
gencia conoce la realidad e inventa posibilidades, ambas cosas las hace gestando y gestionando la irrealidad" (1993, p. 24) y también nos anota: "crear es inventar posibilidades" (p. 21). Vemos cómo al fin de cuentas la inteligencia creadora es aquella que construye posibilidades, o sea, estas no son necesariamente solo las que se me presentan a cada momento como parte de mi entorno y de las cuales debo seleccionar una, además como observador puedo transformar lo que me circunda. De hecho, la materia misma no es como la interpretamos, la materia es producida por las vibraciones rápidas de partículas, a este respecto Leonardo Boff (2010) relata:

En realidad, nosotros percibimos la materia como algo sólido porque las vibraciones de la energía son tan rápidas que no alcanzamos a percibirlas con los sentidos corporales. Pero para eso nos ayuda la física cuántica, justamente porque se ocupa de las partículas y de las redes de energía, que nos abren esta visión diferente de la realidad. La energía es y está en todo. Sin energía nada podría subsistir. Como seres conscientes y espirituales, somos una realización complejísima, sutil y extremadamente interactiva de energía.

Además como observadores construimos la realidad, "un átomo solo aparece en un lugar determinado cuando es medido, en otras palabras, un átomo está extendido en todas partes hasta que un observador consiente decide mirarlo" (YouTube, 2010).

Entonces podemos ver cómo nosotros interactuamos con el entorno, y construimos realidades y posibilidades a través de interacciones energéticas. Ellas nos constituyen en complejidad con el todo en una relación espiritual, por tanto somos cuerpo, mente y espíritu en una sola unidad creadora, eso nos permite construir creativamente nuestras posibilidades y realidades. Así que,
¿Qué nos detiene? ¿Qué es lo que hace que no asumamos el rumbo de nuestra existencia? Lo cual hace pensar que esto de normalizar tiene más "cola" de la que imaginamos, de hecho, niega la construcción de posibilidades como la creatividad, ya que generalmente la encasilla en asignaturas llamadas artísticas y las reduce a contenidos de menor importancia, y para colmo de los males, las carreras artísticas son quizá las de mayor riesgo laboral, amén de la concepción industrial de la educación.

\section{Sobre la sincronicidad}

La sincronicidad, concepto acuñado por Carl Jung (1998), es cuando uno o más elementos se sincronizan de forma significativa y de manera no causal. Por lo tanto, no son un asunto del azar, sino de la invocación energética de quien la propicia a través del deseo, el trabajo y los pensamientos que emprende una persona cuando está forjando un proyecto o busca una solución a un problema de forma creativa. El mismo Jung en su ensayo "The Spirit of Psychology" nos relata: "definí la sincronicidad como una relatividad del espacio y tiempo condicionada por la mente" (1998. p. 28). Sin embargo, y a pesar de que pareciera ser un poder especial de nuestra mente en realidad no es así, porque no lo controlamos, sino que lo invocamos, esta es la manera en que Mark Hathaway ha referenciado a este fenómeno. Por tanto, a mi entender, esto no niega la existencia de un ser supremo, de hecho hay personas que oran para que suceda eso que piden y empiezan a ver cómo se desarrollan una serie de cone$x i o n e s$ con personas, acciones, ofertas, $y$ eventos necesarios para la realización de su necesidad o deseo, es en ese momento que, como piezas de rompecabezas, todos los elementos se sincronizan dando sentido al deseo de quien las invocó, es cuando sucede la sincronicidad, esto nos da un mejor panorama de nuestra 
naturaleza espiritual o energética. Mas este fenómeno no es producto del azar, de hecho he visto que algunos piensan que las oportunidades son producto del azar y hay que estar preparados para asumirlas cuando estas llegan, mas esta propuesta lo que nos dice es que nosotros a través de la sincronicidad podemos invocar estas oportunidades, claro está, hay que trabajar y prepararnos para producir esta sincronía. De manera creativa y consciente podemos construir nuestras posibilidades y realidades, y así por lo tanto debemos, como dice Francisco Gutiérrez, "apropiarnos de nuestra historia y de nuestra cultura" (1996, p. 21). Este es un llamado subversivo a construir nuestra cultura e identidad, que no son necesariamente la del discurso impuesto y por supuesto a ser actores activos de nuestra realidad y posibilidades, por lo tanto, de nuestra historia.

\section{Conclusiones}

Es necesario cambiar el discurso pedagógico por uno que permita empoderarnos como personas en la construcción de nuestras potencialidades, oportunidades y realidades, en palabras de Francisco Gutiérrez, un discurso pedagógico crítico $(2014$, p. 7). Por lo anterior, la percepción de la realidad no se trata de ver pasar frente a nuestros ojos lo que sucede, o lo que creemos que sucede; sino que a través de la creatividad hay que ser actores activos de la construcción y constitución de nuestra realidad. Conociendo la sincronicidad podemos generar creativamente nuestras oportunidades y así lograr cambios en nuestra existencia y nuestras realidades. Es por eso que es urgente, hablar de sincronicidad en las aulas.

\section{Referencias}

Arnz, W., Chasse, B., Vicente, M. (2006). ¿Ytú qué sabes? Editorial Palmyra.

Assmann, H. (2002). Placer y ternura en la educación. Madrid: Narcea Ediciones.

Boff, L. (2010). La materia no existe. Diario El País, Costa Rica. Recuperado de: http://www.elpais.cr/ articulos. php?id=33892

Gutiérrez, F. (1996). Mediación pedagógica. Guatemala: IIME/EDUSAC.

Gutiérrez, F. (2011). Educación como praxis política. Diálogos Red. Xátiva. Editorial.

Gutiérrez, F. (2014). El sentido del discurso pedagógico. Serie Holografías. Costa Rica: Universidad de La Salle.

Jung, C. G. (1998). Sincronicidad. Málaga, España: Editorial Sirio.

Marina, J. A. (1993). La teoría de la inteligencia creadora. Barcelona, España: Editorial Anagrama.

O'Brien, E. (2013). Silencio, escucha a las hormigas. En AcercaCiencia. Recuperado de http://www. acercaciencia.com/2013/02/20/silencio-escuchaa-las-hormigas/

YouTube. (2010). El apocalipsis cuántico y el Universo Holográfico. Recuperado de youtube.com https:// www.youtube.com/watch?v=NOUxplzOrNI 